Ein Filmphilosophie-Symposium mit Robert B. Pippin 


\section{Wiener Reihe}

Themen der Philosophie

Herausgegeben von

Cornelia Klinger, Herta Nagl-Docekal, Ludwig Nagl und Alexander Somek

Band 19 


\section{Ein Filmphilosophie- Symposium mit Robert B. Pippin}

Western, Film Noir und das Kino der Brüder Dardenne

Herausgegeben von

Ludwig Nagl und Waldemar Zacharasiewicz

\section{DE GRUYTER}


Gedruckt mit freundlicher Unterstützung der Österreichischen Akademie der Wissenschaften und ihrer Kommission „The North Atlantic Triangle“, der Kulturabteilung der Stadt Wien (MA 7) und der US Embassy Vienna.

ISBN 978-3-11-043785-0

e-ISBN (PDF) 978-3-11-042983-1

e-ISBN (EPUB) 978-3-11-042993-0

ISSN 2363-9237

\section{Library of Congress Cataloging-in-Publication Data}

A CIP catalog record for this book has been applied for at the Library of Congress.

\section{Bibliografische Information der Deutschen Nationalbibliothek}

Die Deutsche Nationalbibliothek verzeichnet diese Publikation in der Deutschen Nationalbibliografie; detaillierte bibliografische Daten sind im Internet über http://dnb.dnb.de abrufbar.

(C) 2016 Walter de Gruyter GmbH, Berlin/Boston

(C) Coverabbildung: Zeichnung von KAFRI

Satz: Frank Hermenau, Kassel

Druck und Bindung: Hubert und Co. GmbH \& Co. KG, Göttingen

@ Gedruckt auf säurefreiem Papier

Printed in Germany

www.degruyter.com 